\title{
Las rentas mínimas en Francia
}

\author{
Eguzki Urteaga
}

Universidad del País Vasco. Departamento de Sociología 1

eguzki.urteaga@ehu.es

Recibido: 30-06-2010

Aceptado: 07-01-2011

\section{Resumen}

Tras situar el debate sobre las rentas mínimas en el contexto europeo, este artículo analiza las prestaciones sociales mínimas en Francia. La creación de la renta mínima de inserción (RMI) por el gobierno de Michel Rocard constituye la culminación de un proceso histórico que rompe con las lógicas categoriales. Más allá de esto, el balance de las prestaciones sociales se ve afectado por su complejidad y por el fracaso relativo de las políticas de inserción social que acompañan a la RMI. La puesta en marcha de la renta de solidaridad activa (RSA) responde a la cuestión de las «trampas de inactividad», pero no pone fin al debate sobre la arquitectura de las rentas mínimas y el rol de la redistribución en la lucha contra la exclusión social y la pobreza, lo que abre la discusión sobre la pertinencia de instaurar una renta básica de ciudadanía.

Palabras clave: política social; prestaciones sociales; renta mínima; Francia.

\section{Abstract. The minimum income in France}

After placing the debate on the minimum income in a European context, this article analyses the minimum social assistance program in France. The creation of a minimum income support allowance (or RMI) by the government of Michel Rocard constitutes the culmination of a historical process that transforms the logical categories. The complexity and relative failure of the insertion policies that accompany the RMI have several effects on the outcome of the minimum income. The creation of anactive solidarity income (or RSA) responds to the problems of "inactivity traps", but it does not put an end to the debate about the architecture of minimum social assistance or the role of income redistribution in the fight against social exclusion and poverty. This debate opens the door for considering instituting a universal basic income.

Key words: social policy; social helps; minimum income; France. 


\section{Sumario}
1. Introducción
4. La creación de la renta
2. Las rentas mínimas en Europa
3. La instauración de las rentas mínimas de solidaridad activa (RSA)
5. Conclusiones
en Francia
6. Referencias bibliográficas

\section{Introducción}

Una décima parte de los ciudadanos franceses y 3,3 millones de hogares galos dependen económicamente de una de las nueve rentas mínimas para poder vivir o sobrevivir. Esta proporción es estable desde hace más de una década, a pesar de los esfuerzos realizados para disminuirla. Esa realidad, enraizada en la sociedad francesa, da cuenta tanto de la necesidad de estos mecanismos de protección como del fracaso relativo de la lucha contra la exclusión social. Su importancia no constituye ninguna evidencia, dado que la Seguridad Social debía proteger al conjunto de la población por un sistema de seguro, en virtud del principio de universalidad. Según los motivos que figuran en la ordenanza fundadora del 4 de octubre de 1945, "la Seguridad Social es la garantía dada a cada uno de que, ante cualquier circunstancia, dispondrá de los recursos necesarios para asegurar su subsistencia y la de su familia en unas condiciones decentes». No en vano, la toma en consideración de nuevos riesgos, no o mal asegurados hasta entonces, así como la crisis económica, han conducido a los poderes públicos a instaurar unas prestaciones subsidiarias a la Seguridad Social.

Estas prestaciones, inicialmente reservadas a unas categorías específicas, agrupadas bajo la denominación genérica y sin contenido jurídico de «rentas mínimas", han tomado una amplitud inédita con la creación de la renta mínima de inserción $(\mathrm{RMI})^{1}$, toda vez que benefician a una parte creciente de la población. Estas rentas conciernen a unos sectores muy diversos de la población (discapacitados, madres solteras, desempleados de larga duración, etc.) y son de una cuantía diferente. Pero solamente una de ellas, la ayuda equivalente de jubilación $(\mathrm{AEJ})^{2}$, permite superar el umbral de pobreza. Los debates que han

1. La renta mínima de inserción (RMI) es una prestación que ha estado en vigor entre el 1 de diciembre de 1988 y el 31 de mayo de 2009. Financiada por el Estado y gestionada por los departamentos, es concedida por las cajas de ayuda familiar (CAF) o la mutua social agrícola (MSA) a las personas sin recursos o que tienen ingresos inferiores a un umbral fijado por decreto.

2. La ayuda equivalente de jubilación (AEJ) constituye una renta de sustitución o complementaria susceptible de ser concedida a las personas que se encuentran sin empleo en contra de su voluntad. Puede ser concedida, en sustitución de la ayuda de solidaridad específica (ASE) o de la renta de solidaridad activa (RSA), a las personas que han agotado sus derechos a las prestaciones por desempleo o que no cumplen las condiciones para beneficiarse de dicho dispositivo. Se habla entonces de la AEJ de sustitución. Asimismo, puede ser concedida a las personas sin empleo como complemento de la prestación por desempleo, con el fin de asegurarles un nivel de renta mínima. Se habla entonces de una AEJ complementaria. 
tenido lugar a lo largo de los últimos veinte años sobre las rentas mínimas se han referido a sus niveles relativos en comparación con el salario mínimo interprofesional $(\mathrm{SMIC})^{3}$ y a su supuesto impacto sobre el empleo. No obstante, en los últimos tiempos, como lo han mostrado los estudios llevados a cabo por la DRESS ${ }^{4}$ con motivo del vigésimo aniversario de la creación de la RMI, la opinión pública ha cambiado parcialmente su valoración y las rentas mínimas han pasado a ser percibidas a veces como «una forma de ayuda desmerecida». Desde el punto de vista económico, las denominadas «trampas de inactividad» han mostrado los efectos potencialmente perversos de estas prestaciones, que pueden conducir al hecho de que un retorno a la actividad profesional se traduzca en un beneficio financiero muy limitado e incluso en una pérdida de ingresos.

La renta de solidaridad activa (RSA) (Urteaga, 2009a), en vigor desde el 1 de junio de 2009, pretende responder a esas críticas. La RSA, que sustituye a la RMI y a otra prestación social, la ayuda de padre aislado (APA) integra en el corazón de su modelo una solución al problema de las «trampas de inactividad", puesto que permite la acumulación sin limitación de duración entre prestación y renta de actividad. De ese modo, aporta un complemento de ingresos a unos trabajadores cuyas rentas son modestas, que hayan pasado o no por fases de inactividad. Amplía así considerablemente el perímetro de las rentas mínimas, tanto por el número de beneficiarios (se esperan cerca de dos millones de nuevos beneficiarios al final de la implementación del nuevo dispositivo), como por su objeto, que no consiste únicamente en asistir a los que están desprovistos de cualquier recurso, sino también en completar las rentas de una parte de los trabajadores. Por otro lado, esta importante reforma no ha agotado el debate sobre las rentas mínimas. La RSA genera nuevas controversias, tanto sobre sus modalidades de puesta en marcha como sobre el propio

3. El salario mínimo interprofesional de crecimiento (SMIC), antiguamente salario mínimo interprofesional garantizado (SMIG), es el salario mínimo horario por debajo del cual ningún trabajador puede ser remunerado. Es revalorizado anualmente el 1 de enero. A diferencia del SMIG, basado en la inflación, el SMIC es revalorizado como mínimo a la mitad del aumento del poder adquisitivo del salario horario de base obrera (SHBO) y puede beneficiarse de un incremento adicional bajo decisión gubernamental. A 1 de enero de 2010, el salario mínimo se sitúa en 1.348,80 euros mensuales brutos, lo que corresponde a 1.055,42 euros mensuales netos.

4. DRESS: Dirección de Investigación, Estudios, Evaluación y Estadística.

5. La ayuda personalizada de autonomía (APA) está destinada a las personas mayores que viven en su domicilio, en su familia o en otra casa, o a las personas acogidas en una residencia de ancianos y que tienen dificultades para realizar las acciones más básicas y sencillas de la vida cotidiana: levantarse y desplazarse, vestirse y salir de casa, preparar la comida y limpiar su hogar. La APA tiene como objetivo prioritario facilitar la vida diaria de estas personas, tanto en sus hogares como en las residencias en las que se encuentran. En su domicilio, la APA financia varios servicios: personal de ayuda a domicilio, acogida de día, acogida temporal, ayudas técnicas, reforma de la vivienda, transportes, etc. En residencia, la APA contribuye a financiar los gastos vinculados a la atención de la dependencia. La residencia puede igualmente concentrar los recursos humanos y materiales sobre esta persona, con el fin de ayudarla en su vida diaria. 
principio del dispositivo. Concebido en un periodo de coyuntura favorable, está implementada en pleno recrudecimiento del desempleo y cuestiona, de manera menos coyuntural, la pertinencia de un dispositivo centrado en la vuelta al empleo.

Este artículo defiende la hipótesis según la cual, tras el incremento de la pobreza y de la exclusión social en Francia (a partir de la década de 1980) como consecuencia de la crisis socioeconómica que ha provocado un aumento del desempleo y de la precariedad laboral, las administraciones públicas galas han puesto en marcha progresivamente una serie de rentas mínimas para asegurar unas condiciones dignas de existencia al conjunto de la ciudadanía. La instauración de la renta mínima de inserción (RMI) por el gobierno de Michel Rocard pretendió, a la vez, asegurar una renta mínima y favorecer la inserción social de los beneficiarios. Entonces quedó de manifiesto la siguiente problemática: aunque se consigue evitar la gran pobreza, sus receptores se mantienen en una situación de vulnerabilidad, además de perjudicar, en ciertas circunstancias, su reinserción laboral. Esta percepción problemática de estas rentas conducirá finalmente al gobierno de Fillon a sustituirla por la renta de solidaridad activa (RSA), que permite compaginar los subsidios y el salario hasta un cierto umbral. Si la RSA se inscribe en un contexto europeo favorable a la activación de los beneficiarios de las rentas mínimas, no resuelve el problema ni de los jóvenes desescolarizados, ni de los mayores parados, ni de las personas sin hogar (Damon, 2002), lo que abre el debate sobre la necesidad de instaurar una renta básica de ciudadanía (RBC).

\section{Las rentas mínimas en Europa}

A partir de la década de 1990, se ha generado en Europa un debate a propósito de las rentas mínimas como herramientas fundamentales para enfrentarse a la pobreza y a la exclusión social (Comisión Europea, 2006). De este modo, una recomendación de 1992 invita a los estados miembros de la Unión Europea a desarrollar las rentas mínimas para garantizar el derecho de acceso a unos recursos y a unos servicios adecuados que aseguren la dignidad de todos los ciudadanos (Unión Europea, 1992). Posteriormente, en el Libro Verde. Política Social Europea. Opciones para la Unión (Comisión Europea, 1993), así como en varias comunicaciones, se hace referencia a esta apuesta por las rentas mínimas a nivel comunitario.

Ello explica que, a lo largo de esa década, se hayan extendido los programas de renta mínima (RM) en la mayoría de los países europeos, lo cual ha propiciado la convergencia de cara a unir dotación económica e inserción social (Moreno, 2008). De la Europa de los quince, todos los países excepto Grecia (Nicaise et al., 2004) se han dotado de un dispositivo que pueda englobarse en las rentas mínimas. Para 1995, exceptuando los países del sur de Europa, el resto disponía de un mecanismo de RM. En España, comienzan a darse los primeros pasos en esta dirección a partir del final de la década de 1980 y a lo largo de la siguiente, aunque su desarrollo sea fragmentario y frágil (Laparra, 
2004a y 2004b). En Portugal, el dispositivo de RM se pone en marcha en 1997, con el nombre de rendimiento mínimo garantizado (RMG) (Capucha, 1998), y, un año más tarde, Italia instaura un mecanismo piloto que se establece a nivel local. La característica común de estos países es que sus programas son de escasa calidad y muy limitados.

En este sentido, la diversidad de los dispositivos de renta mínima aprobados por los estados miembros de la Unión Europea es considerable. Mientras que programas como el «Income support» del Reino Unido deja a sus beneficiarios por debajo del umbral de la pobreza, en Suecia, las rentas mínimas superan ampliamente ese umbral (Behrendt, 2003). Asimismo, la dotación económica de las RM en Letonia se sitúa en 28 euros para una persona sola, mientras que en Dinamarca esta cifra asciende a 1.130 euros (Peña-Casas, 2005), es decir, una cuantía nueve veces superior a la renta mínima portuguesa (Euzéby, 2004). Estas diferencias notables han puesto de manifiesto la necesidad de coordinar y armonizar los dispositivos de los estados miembros a través de las instituciones comunitarias (EAPN, 2006). En esta óptica se inscribe la propuesta de De Giorgi y Pellizzari para crear un renta mínima europea de una cuantía de 430 euros por persona (De Giorgi y Pellizzari, 2006).

La intención de la Comisión Europea es relanzar las rentas mínimas a través de la puesta en marcha de programas de activación, bajo la premisa de que éstos pueden ser unas herramientas eficaces para la inserción y el acceso al mercado laboral (Hanesch y Balzter, 2001; Pérez Eransus, 2004; EAPN, 2005 y 2006), dado que hasta ahora los resultados obtenidos han sido más bien escasos (Aust y Arriba, 2000). Tanto las instancias europeas como varias organizaciones no gubernamentales (Social Plateform, 2006) subrayan la importancia de la activación de las rentas mínimas, aunque su significado pueda variar en función de la opinión del actor elegido (Moreno, 2008). De ese modo, las instancias europeas optan por combinar las rentas mínimas y las PAE, al entender la inserción esencialmente como el acceso al mercado laboral.

Los debates que se están dando en la actualidad a propósito de las RM se sitúan en ese contexto. En Bélgica, se han puesto las bases para introducir la lógica de activación dentro del minimex (Kazepov y Sabatinelli, 2005). En España, Navarra ha sido pionera en esta materia, ya que ha establecido un programa de empleo social protegido de acuerdo con esta lógica de la activación (Pérez Eransus, 2004). A su vez, la Comunidad Autónoma del País Vasco ha explorado vías para la activación a través de seminarios y encuentros que han desembocado sobre la sustitución de la renta básica por la renta mínima de garantía de ingresos, así como por la puesta en marcha de programas de empleo protegido tales como "Auzolan».

Junto a la puesta en marcha de medidas que se refieren a la activación y a las PAE, y con el mismo objetivo de facilitar el acceso al mercado laboral, se han creado unos incentivos al empleo a través de bonificaciones y exenciones fiscales. El hecho de que la mayoría de los empleos a los que aspiran los beneficiarios de la renta mínima sean precarios y de escasa calidad, hace que el riesgo de trampa de la pobreza aumente (Moreno, 2008). Para hacer frente a 
esta situación, los incentivos al empleo se multiplican, como la prima al empleo francesa o los estímulos para el empleo en el País Vasco. En lugar de optar por la sanción, como en el caso del workfare, se privilegia el incentivo. En la Comunidad Autónoma del País Vasco, mediante la orden del 14 de febrero de 2001, se establecen los incentivos al empleo para las personas receptoras de la renta básica (RB) y ayudas de emergencia social (AES), con la finalidad de erradicar los posibles efectos desincentivadores que estas prestaciones pueden tener sobre la búsqueda de empleo. Los incentivos, que empezaron a funcionar en el año 2002, establecen que un porcentaje del salario queda exento a la hora de realizar el cómputo de los recursos para recibir la renta básica. En 2003, en torno al $20 \%$ de las personas receptoras de esta ayuda se beneficiaban de los incentivos al empleo (Moreno, 2008).

Todas estas medidas muestran la relevancia que está tomando el acceso al mercado laboral dentro de las políticas sociales en general y de las políticas de inserción en particular. De hecho, en los diferentes modelos (workfare anglosajón, activación nórdica o solidaridad continental), ese objetivo es uno de los ejes principales de la acción pública. Se observa igualmente una tendencia a la equiparación de los diferentes modelos, más allá de las especificidades políticoadministrativas y culturales, en un proceso de convergencia europea (Moreno, 2008). En el caso de las rentas básicas, encontramos medidas que se inspiran tanto en la activación como en el workfare, así como en una mayor obligación a participar en programas de inserción o la instauración en ciertas rentas mínimas de medidas que obedecen a la lógica del EITC (Earned Income Tax Credit) para estimular el acceso al mercado laboral.

En definitiva, las políticas de rentas mínimas galas se sitúan en un contexto europeo que favorece los procesos de convergencia.

\section{La instauración de las rentas mínimas en Francia}

\subsection{Un largo proceso}

En Francia, las rentas mínimas son una creación reciente aunque constituyan la culminación de un largo proceso histórico.

\subsubsection{Los avatares de la solidaridad}

Bajo el antiguo régimen, la inmensa mayoría de la población vivía en unas situaciones que se considerarían hoy en día como de gran pobreza. No en vano, el panorama social no es uniforme y ciertos colectivos sociales conocen una indigencia aún mayor. Las víctimas de las guerras, de las epidemias y de las hambrunas incrementan el número de mendigos y vagabundos que constituyen una amenaza para la autoridad, puesto que forman los contingentes de las revueltas campesinas. La sociedad considera a estos colectivos con cierta angustia y culpabilidad, y la actitud de las autoridades oscila durante un largo periodo entre la caridad y la represión. Así, la creación de los hospicios en los siglos XVII y XVIII responde a la voluntad de proteger y de cuidar, pero también de marginar. 
El siglo XIX no marca una inflexión clara, dado que el delito de vagabundeo, que figura en el Código Penal de 1810, sólo desaparece en 1994. De hecho, aunque las reflexiones sobre la pobreza se multiplican, la Revolución Industrial centra la cuestión social en el obrero proletario (Castel, 1995). Por lo tanto, el vagabundo y el excluido dejan de ser el corazón de los temores y de las preocupaciones de los poderes públicos. La Tercera República espera más de veinte años antes de abordar el problema de la pobreza, bajo la influencia de ciertos pensadores del radicalismo que consideran que el anclaje de la República pasa por una política de solidaridad en sustitución de la Iglesia y de su caridad (Paugam, 1996).

En esta época se pone en marcha progresivamente una política de asistencia pública a través de cuatro leyes: la Ley del 15 de julio de 1893, sobre los enfermos indigentes y la asistencia médica gratuita; la Ley del 14 de julio de 1905, sobre la asistencia a los ancianos, a los inválidos y a los incurables, y las dos leyes del 19 de julio de 1913, sobre la asistencia de las mujeres embarazadas y de las familias numerosas. Tres principios fundamentales caracterizan a la asistencia pública: 1) la obligación de asistencia depende de las administraciones locales, y se distingue en ese sentido de la caridad; 2) la asistencia está inicialmente asegurada por los ayuntamientos, en una relación de proximidad donde el Estado apenas interviene, y 3) la asistencia es subsidiaria y tiene vocación de sustituir temporalmente la solidaridad familiar. Esto constituye el embrión de lo que se denominará posteriormente «ayuda social» (Urteaga, 2009b).

En 1945, la ambición inicial de la Seguridad Social es marginar estos dispositivos y medidas. No en vano, sus contradicciones exigirán una reactivación de la asistencia bajo otra forma. En efecto, la Seguridad Social obedece a una lógica aseguradora, pero integra la universalidad entre sus principios fundadores (Rosanvalon, 1995). Por lo tanto, es inevitable que se plantee la cuestión inherente a su arquitectura: ¿cómo proteger a los que, no siendo asalariados, no cotizan y no están asegurados? La respuesta viene de vez en cuando y cada prestación social aparece como el complemento de una prestación contributiva:

- En 1956, el mínimo de vejez es instaurado a favor de las personas mayores que no han podido beneficiarse de los derechos a una pensión de jubilación.

- En 1975, la creación de la ayuda para adultos discapacitados (AAD) ${ }^{6}$ permite cubrir las necesidades de unas personas que no tienen derecho a una pensión de invalidez.

- La ayuda de padre aislado (APA), creada en 1976 para los padres que educan solos a sus hijos, es concedida bajo ciertas condiciones de recursos.

6. La ayuda para adultos discapacitados (AAD) es una prestación que tiene como objeto garantizar una renta mínima a las personas discapacitadas para que puedan enfrentarse a los gastos de la vida corriente. Su pago es subsidiario, puesto que el derecho a beneficiarse de la ayuda es efectivo únicamente cuando la persona discapacitada no puede aspirar a una prestación por vejez, invalidez o a una renta por accidente laboral de una cuantía al menos igual al de la AAD. Esta es concedida a partir de un cierto nivel de discapacidad, siempre y cuando cumpla unas condiciones de residencia y de nacionalidad, de edad y de recursos. 
Beneficia así a personas que no cumplen las condiciones de actividad de la ayuda parental de educación (APE) ${ }^{7}$, creada en 1985.

— La ayuda de solidaridad específica (ASE) ${ }^{8}$ es concedida desde 1984 a los desempleados que han agotado sus derechos a la prestación aseguradora del régimen de la UNEDIC?.

Paulatinamente, la financiación de estas prestaciones es distinguida o diferenciada del sistema asegurador. En 1993, la carga del mínimo de vejez es transferida de la rama de jubilación a una entidad pública, el fondo de solidaridad para la vejez $(\mathrm{FSV})^{10}$, que recibe una parte del producto de la contribución social generalizada $(\mathrm{CSG})^{11}$. En 1999, la APA, financiada hasta entonces

7. La ayuda parental de educación (APE) está dirigida a los padres que desean interrumpir o reducir su actividad profesional para cuidar de sus hijos, con la condición de que hayan nacido antes del 1 de enero de 2004. Efectivamente, para los niños que han nacido después de esta fecha, en el marco de la prestación de acogida del niño pequeño (PANP), los padres pueden beneficiarse del "complemento de libre elección de la actividad».

Para beneficiarse de la APE, es preciso tener al menos dos hijos, el último de los cuales tenga menos de tres años. Además, es necesario haber interrumpido o reducido la actividad profesional. Además, es indispensable haber trabajado como mínimo durante dos años en los últimos cinco años. Conviene subrayar que esta prestación es incompatible con las siguientes: la ayuda para el adulto discapacitado, una pensión de invalidez o de jubilación, bajas por enfermedad, maternidad o accidente laboral, unas prestaciones por desempleo.

Esta ayuda puede ser percibida en su totalidad, si el padre ha interrumpido completamente su actividad, o parcialmente, si el padre ha mantenido parte de su empleo. Ambos miembros de la pareja pueden beneficiarse de la APE en su totalidad, aunque no puedan hacerlo simultáneamente. Por el contrario, pueden acumular dos ayudas parciales, con la condición de que su total no supere la cuantía de una prestación completa. La ayuda es concedida hasta el tercer cumpleaños del niño para el cual ha sido solicitada la prestación.

Por último, si el padre que percibe la APE desea retomar su actividad a jornada completa, puede acumular dicha ayuda con su renta, con la condición de que el niño tenga entre dieciocho y treinta meses y durante un periodo máximo de dos meses. Podrá entonces beneficiarse de la ayuda familiar para la contratación de una niñera cualificada.

8. La ayuda de solidaridad especifica (ASE) puede ser concedida, bajo ciertas condiciones de actividad anterior y de recursos, a las personas siguientes: $a$ ) a los trabajadores privados de empleo que han agotado sus derechos a la ayuda de retorno al empleo (ARE) o a la ayuda de fin de formación (AFF); $b$ ) a los beneficiarios de la ayuda de retorno al empleo, de más de cincuenta años, que eligen esta prestación, si su cuantía es superior a la de la ARE, y c) a los artistas no asalariados que no se benefician de la prestación por desempleo.

9. La Unión Nacional Interprofesional para el Empleo en la Industria y el Comercio (UNEDIC, por sus siglas en francés) es una asociación dirigida por los agentes sociales que se encarga de la gestión del seguro por desempleo, teniendo en cuenta que dicho seguro está financiado por las cotizaciones de los trabajadores y de las empresas del sector privado. Asegura una renta de sustitución a los trabajadores involuntariamente privados de empleo y favorece un retorno al empleo a través de la financiación de ayudas y de prestaciones adecuadas.

10. El fondo de solidaridad para la vejez (FSV) es una entidad pública administrativa creada en 1993 y cuya misión consiste en asumir la financiación de las ventajas de jubilación que dependen de la solidaridad nacional.

11. La contribución social generalizada (CSG) es un impuesto instaurado el 16 de noviembre de 1990 que participa de la financiación de la Seguridad Social. Esencialmente, es recaudado por la URSAFF y su naturaleza ha sido objeto de debate. Así, el Tribunal Constitucional considera que se trata de un impuesto y no de una cotización social. En realidad, la CSG 
por la rama familiar, es asumida por el Estado, lo que es también el caso de la AAD y de la ASE. Esto da cuenta de la voluntad de distinguir más claramente las prestaciones que obedecen a una lógica aseguradora de las que se refieren a una lógica asistencial.

\subsubsection{La revolución de la $R M I$}

A lo largo de la década de 1970, se hace patente que las situaciones de gran pobreza han sobrevivido a la puesta en marcha de la Seguridad Social y de las primeras prestaciones sociales y que tienen tendencia a incrementarse con la crisis económica. Algunas reflexiones permitirán que la opinión pública tome conciencia de estos retos. En 1974, el ensayo de René Lenoir, titulado Les exclus, un Français sur dix (1974), conoce un gran éxito en esta línea. En 1978, el informe Péquignot preconiza un fortalecimiento de las políticas sociales y sectoriales encaminadas al tratamiento de la gran pobreza. En 1987, el Consejo Económico y Social aprueba el informe del Padre Wresinski, fundador de ATD QuartMonde, titulado Gran pobreza y precariedad económica y social. La precariedad es definida como «la ausencia de una o de varias seguridades, especialmente la del empleo, lo cual permite a las personas y a las familias asumir sus obligaciones profesionales, familiares y sociales, así como disfrutar de sus derechos básicos». Para el Padre Wresinski, las políticas puntuales han mostrado sus límites y conviene poner en marcha un tratamiento integral de la pobreza, que integre una serie de recursos y tome en consideración el conjunto de las necesidades básicas del individuo: vivienda, sanidad, empleo, formación, etc.

La elección presidencial de 1988 acelera este proceso, dado que la puesta en marcha de una renta mínima figura en la Carta a los franceses del candidato François Mitterrand: «Pediré, por lo tanto, al próximo gobierno que sea concedida una renta mínima a las víctimas de la nueva pobreza». Esta idea había avanzado en el seno de la clase política, cada vez más sensibilizada por el problema de la exclusión (Damon, 2008). Así, la ley que instaura la renta mínima de inserción (RMI) es aprobada por unanimidad en las dos asambleas y promulgada finalmente el 1 de diciembre de 1988.

La renta mínima de inserción es un dispositivo novedoso en varios aspectos. Rompiendo con la lógica de las rentas categoriales que prevalecía hasta entonces en materia de prestaciones sociales, la RMI es una prestación universal, que constituye la última red de seguridad para el conjunto de las personas que no disponen de ingresos suficientes para vivir. A partir de 1989, cualquier persona de más de veinticinco años (las personas responsables de varios hijos pueden, sin embargo, cobrar el RMI antes de cumplir los veinticinco años) que resida legalmente en el territorio nacional y cuyos recursos sean inferiores al mínimo garantizado, puede solicitar la percepción de la renta mínima de inserción.

cubre una serie de contribuciones sobre las siguientes rentas: las rentas de actividad y de sustitución, así como las rentas del patrimonio y del capital. La CSG difiere de las cotizaciones sociales en que su pago no confiere ningún derecho de afiliación a los regímenes sociales ni de obtención de prestaciones sociales. 
Las cajas de ayuda familiar $(\mathrm{CAF})^{12}$ se lo pagan cada mes. La creación de la RMI marca una etapa fundamental en la lucha contra las exclusiones, porque, contrariamente a las demás prestaciones de ayuda social, centradas en unas necesidades que es preciso demostrar, consiste en una prestación de solvencia global, vinculada únicamente al nivel de los recursos (Thevenet, 1994).

La segunda innovación se refiere a la combinación de una prestación con un dispositivo de inserción: teóricamente, cualquier beneficiario tiene el derecho y el deber de firmar con la Administración local un contrato de inserción, concertado con él, que prevé el conjunto de las acciones de inserción social o profesional adaptadas a su situación. Puede beneficiarse, por ejemplo, de unas intervenciones destinadas a resolver sus dificultades de salud, de vivienda, de acceso a la formación o al empleo. Se crea una delegación interministerial de la RMI, la DIRMI, para implementar una política que implica a numerosos ministerios. Además de las acciones de acompañamiento puestas en marcha sobre el terreno, son instaurados numerosos «derechos conexos» a favor de los beneficiarios de la RMI, con el fin de tratar el conjunto de estas dificultades, en conformidad con los principios enunciados por el informe Wresinski. Así, el informe de 2005 de la senadora Valérie Létard registra los derechos conexos legales y específicos vinculados al estatus del «rmista»: el acceso preferente a las ayudas a la vivienda, unas ventajas fiscales, la exoneración de la CRDS ${ }^{13}$ y de la CSG, pero también la prima de Navidad, la tarificación social del teléfono, el acceso automático a la CMU (Cobertura Médica Universal) ${ }^{14}$ complementaria, así como diversas ayudas locales (gratuidad de los transportes urbanos, del comedor escolar, etc.). Otras prestaciones sociales existentes dan también acceso a unos derechos conexos, pero de manera variable.

\subsection{El balance de las rentas minimas}

El balance de las rentas mínimas se ve afectada por su complejidad y por el fracaso relativo de las políticas de inserción que acompañan a la RMI.

12. La caja de ayuda familiar (CAF) es la representación local de la caja nacional de ayudas familiares (CNAF), que constituye la rama familiar de la Seguridad Social. Cada CAF es un organismo de derecho privado con competencias territoriales que se encarga de pagar a los ciudadanos unas prestaciones con carácter familiar o social, en unas condiciones determinadas por la ley. Cada CAF asegura, además, a nivel local, una acción social fundamentalmente colectiva para una ayuda técnica y unas subvenciones dirigidas a los actores locales de la vida social (ayuntamientos, guarderías, centros de ocio, etc.). Existen actualmente 123 cajas de ayuda familiar sobre el territorio francés, con un mínimo de una por cada departamento.

13. CRDS: contribución para el reembolso de la deuda social.

14. La cobertura médica universal (CMU) es una prestación social que permite el acceso a la atención médica, al reembolso de dicha atención y a los medicamentos para cualquier persona que reside en Francia y que no está cubierta por el régimen obligatorio de seguro de enfermedad. Este dispositivo ha sustituido a la "carta salud», que dependendía de los departamentos y que aseguraba hasta entonces unas prestaciones similares. Aprobado en 1999 por la Asamblea Nacional y puesto en marcha en 2000, este dispositivo descentralizado está gestionado por la URSAFF. 


\subsubsection{Unas cuantías variables pero distantes del salario minimo}

Si la RMI estaba destinada a todos aquellos que no disponían de recursos mínimos para poder vivir, su puesta en marcha no ha provocado la supresión de las demás prestaciones sociales. Se siguen concediendo estas prestaciones a sus diferentes beneficiarios manteniendo su singularidad. En ciertos casos, los beneficiarios de dichas prestaciones han cobrado incluso el saldo de la RMI. Efectivamente, una de las características comunes de las rentas mínimas es que son diferenciales, es decir, que están limitadas a un nivel de renta y que constituyen un complemento que permite alcanzar ese umbral.

Por ejemplo, la cuantía de la RMI por persona es de 455,63 euros desde el 1 de enero de 2009. Si una persona dispone de 300 euros, incluyendo una prestación social, cobrará 455,63 €-300 €=155,63 € de la RMI. Por lo tanto, las prestaciones sociales son acumulativas, pero jamás podrá cobrarse más que la cuantía de la prestación más elevada. No en vano, estas ayudas, provenientes de políticas públicas dirigidas a diferentes colectivos (discapacitados, pobres, desempleados de larga duración, padres aislados), no están siempre separadas, dado que es posible formar parte de varias de ellas, porque han sido elaboradas según unas lógicas diversas, y sus cuantías son también muy diferentes. Así, la ayuda equivalente por jubilación (AEJ) es una renta relativamente importante, próxima al salario mínimo (SMIC) a jornada completa, mientras que la ayuda de viudedad sólo representa un tercio.

Además, si el carácter diferencial es común al conjunto de los dispositivos y de las medidas, las modalidades de gestión de los recursos son tan variadas como las prestaciones, cuyas reglas de cálculo jamás han sido armonizadas. Así, las ayudas familiares son tomadas en consideración en el cálculo de la RMI, pero no en el de la ASE. Resulta de todo ello una gran complejidad para los beneficiarios potenciales, que deben tener un cierto conocimiento de la reglamentación para determinar a qué prestaciones sociales tienen derecho, con qué cuantía y para qué duración, dado que ciertas prestaciones como la APA son concedidas durante un periodo limitado. En su diversidad, las rentas mínimas presentan, asimismo, una segunda característica común: su indexación sobre el índice de los precios. Esto permite evitar una pérdida de poder adquisitivo, pero incrementa cada vez más la diferencia entre los trabajadores a jornada completa y los beneficiarios de estas prestaciones, es decir, entre los incluidos y los excluidos.

A pesar de la diferencia existente entre las prestaciones, se observa una disminución continua con respecto al salario mínimo, que alcanza el 16\% durante ese periodo. De manera más significativa todavía, el número de horas de trabajo necesarias para ganar el equivalente de una renta mínima ha disminuido en un porcentaje superior al 22\% durante ese periodo. En el debate sobre las «trampas de inactividad», esta constatación nos invita a relativizar los argumentos concernientes al nivel demasiado elevado de dichas prestaciones.

\subsubsection{Una extensión inesperada y un fracaso relativo}

La prueba del interés de la RMI estriba en la rápida extensión del número de beneficiarios desde la creación de este dispositivo en 1988. Las proyecciones 
realizadas antes de la creación de la RMI consideraban que unas 500.000 personas se beneficiarían de este nuevo dispositivo, pero, en algunos años, esta cifra se ha duplicado. Dos razones pueden explicar esta superación: por una parte, el nivel inicial de la necesidad social había sido infravalorada y la creación de la RMI ha revelado ciertas formas de pobreza ignoradas por los poderes públicos, especialmente la de un gran número de hombres aislados, $y$, por otra parte, las reformas restrictivas del seguro de desempleo, sobre todo las que han acontecido entre 1993 y 2003, han provocado una transferencia automática hacia la RMI. Los episodios de retroceso del desempleo en el período 1997-2001 y en el período 2005-2008 no han permitido invertir la tendencia alcista, sino que, en el mejor de los casos, la han estabilizado, ya que los beneficiarios de la RMI, que a menudo sufren una gran dificultad, son los últimos en beneficiarse de los episodios de reactivación económica.

El número de beneficiarios de la RMI depende ampliamente de factores externos al propio dispositivo, como la tasa de desempleo o las reglas de indemnización definidas por la UNEDIC. Por lo tanto, no permite medir la eficacia del dispositivo de inserción propia de la RMI. Por el contrario, la antigüedad media de los beneficiarios es un buen indicador de la eficacia de las políticas de inserción.

Se observa que si la cuarta parte de los receptores ha entrado en el dispositivo desde hace menos de un año, cerca de un tercio cobra la RMI desde hace más de cinco años. Para ellos, la perspectiva de inserción se ha alejado duraderamente y las perspectivas de retorno al empleo aparecen limitadas, porque el mercado laboral francés estigmatiza a menudo a las personas que han conocido unos largos periodos de inactividad. Sin embargo, este fracaso de las políticas de inserción no significa que no hayan surtido efecto. En 2007, la cuantía del gasto medio de inserción ha sido de 1.149 euros, es decir, el $16,7 \%$ de la cuantía de las prestaciones concedidas. Incluyendo los contratos subvencionados, el gasto global ascendía a 1,18 billones de euros. No en vano, las estadísticas nacionales no son en absoluto alentadoras, puesto que la salida de la RMI es difícil.

La Ley del 18 de diciembre de 2003, relativa a la descentralización de la renta mínima de inserción, que ha transferido la competencia de gestionar la prestación a los consejos generales y que ha puesto fin a la dirección compartida entre el Estado y los departamentos de la política de inserción, resulta de esta constatación de fracaso de la inserción. Los departamentos ejercían, efectivamente, un rol importante en materia de inserción desde la creación del dispositivo, pero la eficacia en la gestión no estaba incentivada financieramente, puesto que el pago de la prestación estaba asumido por el Estado. La descentralización de la RMI es atípica y no corresponde a un esquema habitual: aunque una administración local decida fomentar la construcción de unas carreteras, de unos centros educativos o de unas formaciones situadas bajo su responsabilidad, la reglamentación de la RMI sigue siendo nacional y el departamento debe afrontar la evolución del número de beneficiarios, que depende de la situación macroeconómica. Además, la gestión operativa de la prestación sigue 
estando confiada a las cajas de ayuda familiar (CAF). Sin embargo, el rol del departamento es sustancial. En lo que se refiere a la prestación, se convierte en el comanditario de las CAF en lugar del Estado, ya que puede orientar las modalidades de gestión y de control de dichas cajas. Decide plenamente sobre su política de inserción, dado que la Ley del 18 de diciembre de 2003 le confiere la responsabilidad del control de los contratos subvencionados.

Las polémicas sobre el nivel y la evolución en el tiempo de la compensación financiera concedida por el Estado han oscurecido el balance de la descentralización (CNAF, 2007). La Constitución impone que se proceda a la transferencia hacia las administraciones concernidas de los recursos equivalentes a las que asumía hasta entonces el Estado, lo que se ha hecho para la RMI. La dificultad apareció posteriormente, dado que el gasto de la RMI progresaba rápidamente, mientras que los recursos transferidos (una parte del impuesto interior sobre los productos petrolíferos o IIPP) eran inferiores. La lógica de la descentralización, que implicaba la responsabilidad financiera de la Administración local, excluía que el Estado reembolsara cada año a los departamentos lo que habían gastado. No en vano, dado que la posición contraria, que excluía cualquier revalorización de la dotación de transferencia, era difícilmente sostenible, los determinantes del gasto de la RMI escapaban ampliamente a los consejos generales. En 2005, se ha llegado a un consenso con un incremento de 500 millones de euros cada año en lo que se refiere al IIPP transferido, que cubre cerca de la mitad de la diferencia entre ingresos y gastos (DRESS, 2007). Sin embargo, el déficit acumulado por los departamentos es de dos billones de euros al final de 2008.

A pesar de esas dificultades, que han conducido a que la Asamblea de los Departamentos de Francia (ADF) ${ }^{15}$ solicite una nueva centralización de la financiación de la RMI, las evaluaciones llevadas a cabo por la IGAS ${ }^{16}$ (2006 y 2009) y por la DRESS (2007) dan cuenta de la implicación activa de la mayoría de los consejos generales en el desarrollo de las políticas de inserción. Numerosos departamentos han reforzado los recursos humanos dedicados a la inserción y han reorganizado sus colaboraciones imponiendo a las estructuras que acompañan a los beneficiarios una remuneración en función del resultado, o han reactivado de manera sistemática las prestaciones. Asimismo, el éxito de estas iniciativas es variable según los territorios, y los departamentos no disponen siempre de los instrumentos de gestión adecuados. Además, los departamentos que presentan las situaciones económicas más difíciles son precisamente aquellos donde la carga de la prestación es más pesada y la necesidad

15. La Asamblea de los Departamentos de Francia (ADF) es una asociación que representa, de manera pluralista, a todos los departamentos galos y que es miembro de la Casa europea de los poderes locales franceses. La ADF ofrece, a los cargos electos y a los técnicos departamentales, la posibilidad de confrontar sus ideas, de intercambiar sus experiencias y de aprobar unos posicionamientos comunes sobre los grandes temas nacionales. Está presidida desde 2004 por Claudy Lebreton, presidente del Consejo General del Departamento de las Côtes-d'Armor, y dirigida desde 2006 por Michel Rouzeau.

16. IGAS: Inspección General de los Asuntos Sociales. 
de las políticas de inserción es mayor. Las reglas de compensación financiera, basadas en la situación de 2003, toman en consideración esta situación de manera imperfecta (Avenel, 2005).

\section{La creación de la renta de solidaridad activa (RSA)}

La renta de solidaridad activa (RSA) responde a la cuestión de las «trampas de inactividad», pero no pone fin a los debates sobre la arquitectura de las rentas mínimas y el papel de la redistribución en la lucha contra la pobreza.

\subsection{Una respuesta a los trabajadores pobres y a las trampas de inactividad}

\subsubsection{Un proyecto que persigue varios objetivos}

Si las críticas sobre el impacto de la RMI se han concentrado en el fracaso relativo de las políticas de inserción, el problema de las "trampas de inactividad" ha concentrado las reflexiones sobre la evolución del dispositivo. El fenómeno de las trampas es inherente a las rentas mínimas: su carácter diferencial implica que disminuyen con el incremento de las rentas de actividad. Además, a la pérdida de la prestación mínima se añaden unos gastos vinculados al ejercicio de una actividad profesional (transporte, cuidado de los niños, vestido). En definitiva, la vuelta al empleo no mejora sistemáticamente el nivel de vida, más aún cuando el empleo está poco remunerado o es precario.

Esta dificultad fue identificada tras la creación de la RMI en 1988, cuando se puso en marcha un sistema de incentivos para solucionarla. El incentivo consiste en autorizar la acumulación de una parte de la prestación con las rentas de actividad durante un periodo limitado, posterior a la vuelta al empleo. Este incentivo ha sido reformado en varias ocasiones, especialmente por la Ley de orientación, del 29 de julio de 1998, relativa a la lucha contra las exclusiones, y por la Ley del 23 de marzo de 2006, relativa al retorno al empleo y a los derechos y deberes de sus beneficiarios potenciales. Sin embargo, estas reformas no podían compensar el principal límite del incentivo, es decir, su carácter temporal (un año en el dispositivo aprobado en 2006): un sistema reservado a los beneficiarios de las rentas mínimas no puede ser creado permanentemente sin generar una grave desigualdad entre los trabajadores que han transitado por estos dispositivos y los que no se han beneficiado de ellos.

A partir del año 2000, un informe de la comisaría general al plan ${ }^{17}$ preconiza una reforma en profundidad y cuestiona el carácter diferencial de las prestaciones mínimas. Propone sustituirlas por una prestación decreciente, es decir, una prestación que disminuiría a un ritmo menor que el aumento de las rentas de actividad. Por ejemplo, para una renta garantizada de 455,63 euros y un retorno a la actividad que procura un salario de 300 euros, no se deducirían 300 euros de la prestación, sino solamente una parte. Esto conduciría a una

17. Commissariat General Au Plan (2000), Minimas sociaux, revenu d'activité et précarité, rapport du Commissariat général au plan, coordonné par Jean-Michel Belorgey. 
prestación de 305,63 euros y a una renta total (salario + prestación) de 605,63 euros. Así, la acumulación autorizada entre prestación y renta de actividad sería permanente.

En definitiva, se trata de una proposición similar a la propuesta formulada por la comisión «Familias, vulnerabilidad y pobreza» ${ }^{18}$ presidida por Martin Hirsch en 2005, que la denomina «renta de solidaridad activa (RSA)». Aunque la Comisión Hirsch no es la primera en contemplar esta pista, inicia una nueva perspectiva ante esta situación. Efectivamente, la comisión identifica los efectos redistributivos de semejante reforma: el reto no es solamente incitar a los beneficiarios de rentas mínimas a retomar una actividad laboral, sino también aportar un complemento de ingresos sustancial para la categoría de los trabajadores pobres (Hirsch y Villeneuve, 2006). En el centro de esta reflexión, se encuentran ciertos hogares que disponen de rentas de actividad de una cuantía demasiado elevada para poder beneficiarse de la RMI, pero demasiado escasa para permitirles superar el umbral de pobreza. Este fenómeno se produce, por ejemplo, cuando una persona trabaja a jornada parcial o cuando un salario relativamente bajo debe cubrir las necesidades de varias personas.

En este aspecto, el Reino Unido se había adelantado a Francia, puesto que, a partir de 1998, se dotó de un objetivo cuantificado de reducción de la pobreza: Tony Blair se había comprometido a erradicar la pobreza de los niños para 2020. Los niños pobres son aquellos que pertenecen a una familia cuya renta por unidad de consumo es inferior al $60 \%$ de la renta media. Esta focalización en la pobreza de los niños puede explicarse por una filosofía liberal, porque, si es posible pensar que un adulto es parcialmente responsable de su situación de pobreza, es difícil defender esa idea para un niño. En Francia, la pobreza de los niños es uno de los indicadores seleccionados por el decreto del 20 de mayo de 2009, pero no es el indicador central.

En Francia, estos trabajadores pobres escapan al sistema de las rentas mínimas. No en vano, se les dedican ciertas prestaciones, empezando por la prima para el empleo $(\mathrm{PPE})^{19}$. Este crédito de impuestos, creado en 2001, tiene sin embargo numerosos defectos respecto a los objetivos perseguidos: está concedido con un año de retraso y su baremo es demasiado débil y extenso para sacar eficazmente de la pobreza a los trabajadores más precarios. La idea de la comisión es integrar la PPE y sus objetivos en la nueva prestación. Al contrario de sus antecesores, Martin Hirsch no quiere crear una nueva prestación, sino

18. Au possible, nous sommes tenus. La nouvelle équation sociale, rapport de la commission «Familles, vulnérabilité, pauvreté», abril 2005.

19. La prima para el empleo (PPE) es una ayuda de retorno al empleo o a la continuación de una actividad profesional que se calcula en función de las rentas de actividad. En este sentido, no está calculada según las rentas de sustitución (jubilaciones, prestaciones por desempleo, etc.) ni en función de las prestaciones sociales, de las rentas mínimas y de las rentas del patrimonio. Ha sido concedida en septiembre de 2010 a las personas que han ejercido durante el año 2009 una actividad profesional asalariada o autónoma, que están empadronadas en Francia y que pertenecen a un hogar fiscal que disponga de unas rentas que no superen ciertos límites. 
sustituirlas todas por una sola. Por lo tanto, el proyecto de reforma presentado es especialmente ambicioso y persigue cuatro objetivos:

- Poner fin a las «trampas de inactividad».

- Reducir la pobreza, aportando un complemento de renta sustancial a unos trabajadores cuyo salario es modesto.

- Simplificar las prestaciones sociales, cuyo número y complejidad no permiten llevar a cabo una política coherente y eficaz de lucha contra las exclusiones.

- Reformar las políticas de inserción, para establecer una contractualización más efectiva entre el beneficiario de la prestación y la Administración pública.

\subsubsection{Una puesta en marcha novedosa}

El informe Hirsch despertó inmediatamente el interés de los poderes públicos. Antes de la elección presidencial de 2007, fue objeto de un consenso político muy amplio (fue incluido en la plataforma de los dos candidatos elegidos para la segunda vuelta) y dos leyes sucesivas, la Ley de finanzas para 2007 y la Ley a favor del trabajo, del empleo y del poder adquisitivo, conocida como ley TEPA, del 21 de agosto de 2007, que habilitan los consejos generales que lo desean a experimentar una "renta de solidaridad activa» inspirada en unos trabajos de la comisión (Gomel y Severin, 2009). Se trata de la primera aplicación de uno de los dispositivos provenientes de la revisión constitucional de 2003, el artículo 72 de la Constitución, que permite a las administraciones locales voluntarias aprobar unas deliberaciones que derogan la ley y el reglamento.

Después de esta fase de experimentación, la RSA se extiende al conjunto del territorio metropolitano (la extensión a los departamentos de ultramar, con posibles adaptaciones, debe producirse antes del 1 de enero de 2011) por la ley del 1 de diciembre de 2008 y entra en vigor el 1 de junio de 2009. La nueva prestación sustituye a la RMI y a la APA. Como la RMI, la RSA garantiza, para cualquier individuo beneficiario de la prestación, una renta mínima mensual, cuya cuantía está establecida en función de la situación familiar del interesado. Así, en 2009, un soltero sin ingresos puede cobrar 454,63 euros al mes. Conviene observar que, para los beneficiarios de la RMI que no disponían de una renta de actividad, el paso a la RSA no provoca ningún cambio en cuanto a la cuantía de su prestación. La financiación de esta parte de la prestación continúa siendo asumida por los departamentos.

De conformidad con los objetivos de la comisión Hirsch, la RSA aporta una renta complementaria a las personas que trabajan. El nuevo dispositivo puede ser acumulado con la renta de actividad, con la condición de que éste no supere un cierto nivel (1,1 SMIC por persona). Ha sido elaborado de tal forma que cualquier persona que inicie o incremente su actividad profesional, mantenga el $62 \%$ de los beneficios generados por su salario adicional. En otras palabras, la cuantía deducida de su prestación es comparable al 38\% de ese suplemento, mientras que, en el sistema anterior, la 
cuantía deducida era comparable al 100\%. La RSA tiende, por lo tanto, a favorecer la vuelta a la actividad, que es financieramente más atractiva a largo plazo, lo que representa una novedad radical en el dispositivo francés de las rentas mínimas.

La creación de esta nueva prestación se ha acompañado de una reforma de las políticas de inserción. Mientras que el contrato de inserción de la RMI podía referirse indiferentemente a unas acciones de inserción social o profesional, la Ley del 1 de diciembre de 2008 convierte la inserción profesional en su prioridad: cualquier beneficiario de la RSA que no trabaja o sólo percibe unas rentas muy bajas de su trabajo debe, en teoría, inscribirse en una trayectoria de inserción profesional, excepto si unas dificultades sociales especialmente importantes, sobre todo de salud o de vivienda, lo imposibilitan temporalmente.

Así, la Ley consagra y acelera una evolución constatada desde la descentralización de la RMI, dado que un gran número de programas departamentales de inserción ponen el énfasis en las acciones con carácter profesional. La Ley plantea la obligación para el Polo Empleo de asegurar gratuitamente el acompañamiento de los beneficiarios de la RSA orientados hacia ella por el departamento. El objetivo del gobierno es duplicar la tasa de beneficiarios inscritos en la lista de parados, que era hasta entonces del 33\%. Los beneficiarios de la RSA inscritos en el Polo Empleo están sometidos a las mismas obligaciones que los demás desempleados, especialmente la búsqueda activa de empleo y la aceptación de las ofertas razonables de empleo. Un rechazo puede conducir, según la valoración del presidente del Consejo general, a una reducción e incluso a una supresión de la RSA.

Es interesante observar que la integración de la APA en la RSA se produce en el caso de aquellas personas que percibían esta prestación por la aplicación de los mismos derechos y deberes en materia de inserción, mientras que ninguna regla de ese tipo existía para la APA. Se trata de un profundo cambio con respecto a la vocación inicial de esta prestación, que, por ejemplo, debía permitir a una madre aislada cuidar de su hijo durante tres años. A partir de entonces, el objetivo es preparar la reinserción, incluso si la Ley impone tener en cuenta unas cargas especiales vinculadas al cuidado de un niño en la definición de las obligaciones de inserción.

\subsection{La perpetuación del debate sobre las rentas minimas}

La RSA no ha puesto fin al debate sobre la arquitectura de las rentas mínimas ni sobre los instrumentos de lucha contra la pobreza.

\subsubsection{Las criticas formuladas sobre el principio y las modalidades de la RSA}

Las principales críticas formuladas en contra de la RSA son de tres tipos. Se refieren: 1) a las condiciones de experimentación del dispositivo; 2) a la diferencia existente entre la ambición inicial y la realización, y 3) a una oposición más fundamental hacia el propio proyecto. 
El primer reproche concierne a las condiciones de experimentación del dispositivo, presentado por sus promotores como un modelo inédito. La voluntad de evaluar un dispositivo de esta amplitud antes de su implementación legislativa constituía efectivamente una novedad y daba cuenta de la voluntad de los actores implicados de romper con la lógica de los dispositivos precedentes. No en vano, este planteamiento ha sido objeto de ciertas críticas (Cahuc, 2009; Gomel y Severin, 2009), sobre todo porque el dispositivo experimentado difería de la prestación finalmente aprobada por el legislador. En particular, solamente los beneficiarios de las rentas mínimas que encontraban un empleo eran elegibles al dispositivo experimental, mientras que los trabajadores con ingresos constantes que no habían recibido ninguna prestación no podían recibir la RSA generalizada.

El carácter inacabado de la simplificación con respecto a las ambiciones iniciales del informe Hirsch ha sido igualmente estigmatizado. Así, la ayuda de solidaridad específica (ASE) ha sido mantenida, así como el dispositivo de prima para el empleo (PPE). La voluntad manifestada de proceder a una notable simplificación de las prestaciones sociales y de integrar los instrumentos de lucha contra las «trampas de inactividad» no ha conseguido los resultados esperados. Es posible acumular la ASE y la RSA, y los hogares que tienen una renta de actividad por unidad de consumo superior al salario mínimo (SMIC) continúan cobrando la prima para el empleo, que desaparece sin embargo a partir de ese umbral. Otro elemento a considerar que permanece abierto es la integración del conjunto de los beneficiarios de las prestaciones en un dispositivo de inserción profesional coherente. Se enfrenta a las dificultades del Polo Empleo para hacer frente al incremento del desempleo generado por la crisis económica.

Otras críticas a la RSA conciernen a la ambición que se halla en el centro del dispositivo. Para ciertos observadores, la renta de solidaridad activa abandona definitivamente la ambición de integración de la RMI. Completando la renta de los trabajadores pobres, se acusa a la RSA de favorecer una perpetuación de las formas particulares de empleo y de contribuir así a la precarización del asalariado. Además, se acusa a la RSA de poner fin a la tradición francesa de la ayuda social exigiendo una contrapartida al beneficiario, que debe buscar activamente un empleo remunerado si no quiere asistir a la suspensión de su prestación. Se zanjaría así la ambigüedad de la RMI, renta mínima y prestación de inserción, en detrimento de la primera. Para Jacques Rigaudiat (2009), la RSA ha abandonado la lógica de «red de seguridad» para adherirse a una "ilusión individualista». El alcance de estas críticas solo podrá valorarse después de las primeras evaluaciones del impacto de la prestación. La evolución de la tasa de empleo precario nos dirá si la RSA ha surtido algún efecto sobre su crecimiento y la tasa de suspensión de la prestación nos informará sobre el endurecimiento de la política de concesión. La capacidad del Polo Empleo a reintegrar los beneficiarios de las prestaciones en el mundo laboral permitirá evaluar la pertinencia del énfasis puesto sobre la inserción profesional. 


\subsubsection{Las cuestiones no resueltas de la RSA}

Algunas propuestas de la comisión Hirsch sólo han recibido una respuesta parcial con la puesta en marcha de la RSA. Se trata, fundamentalmente, de la unificación de las rentas mínimas y de la lucha contra la pobreza. Más allá de estas críticas, es importante medir las perspectivas de evolución de estos dos temas, mientras que la nueva prestación apenas empieza su existencia. La unificación de las prestaciones sociales constituye un debate recurrente entre los actores de la acción social desde la década de 1980, y la RSA sólo ha unificado la RMI y la APA. Por lo tanto, se plantea la cuestión de saber si conviene proseguir la integración de las rentas mínimas. En la práctica, la situación varía según la prestación a la que conciernen:

- Las prestaciones próximas a la RSA, tanto a nivel del baremo como de las condiciones de concesión. Estas prestaciones podrían ser integradas en la RSA, lo que simplificaría la comprensión de los dispositivos por los beneficiarios y mejoraría la coherencia de las políticas sociales. Se trata fundamentalmente de la ayuda de solidaridad específica (ASE).

- Otras prestaciones mínimas, tales como la ayuda para adultos discapacitados (AAD), se sitúan a unos niveles muy superiores a los de la RSA y conciernen a unos colectivos específicos. Su integración en el dispositivo plantearía notables problemas técnicos, especialmente la instauración de baremos distintos, y la multiplicación de las condiciones de acceso complejizaría la RSA sin beneficio evidente para los beneficiarios.

La integración de las rentas mínimas presentaría sin duda un balance entre coste y beneficio positivo para el primer tipo de prestaciones, mientras que el debate está más abierto para los demás. Incluso en el caso de la ASE, las dificultades de puesta en marcha no deben ser infravaloradas. Asimismo, la diferencia de baremos y las condiciones de admisión plantean la cuestión de los perjudicados. Un estudio realizado en el marco de las experimentaciones de la RSA muestra que su número sería significativo ${ }^{20}$. Además, los beneficiarios de la ASE gozan de la validación de trimestres de cotización para el cálculo de su pensión de jubilación, ventaja que no existe para todos los beneficiarios de la RSA. Por otro lado, la lógica de integración de los dispositivos supone que se suprima la PPE «residual», puesto que ya ha sido absorbida por la RSA para las remuneraciones inferiores al salario mínimo. Esta supresión permitiría simplificar el sistema de prestaciones y poner fin a los defectos de la PPE. No obstante, se enfrenta a unos obstáculos políticos, porque perjudicaría necesariamente a algunos beneficiarios actuales.

El tema de la lucha contra la pobreza es, sin duda, menos polémico, pero no menos grave. El objetivo fijado a la RSA es disminuir en un tercio el número de trabajadores pobres. La cuestión de los recursos que conviene movilizar para ir más allá de este objetivo sigue planteándose, así como la de la pobreza de las

20. Agence Nouvelle des Solidarités Actives (2008). Étude sur l'accès au RSA des bénéficiaires de l'ASS et de l'ARE. 
personas que no trabajan. Francia podría enfrentarse al mismo bloqueo que el Reino Unido. Después de los avances importantes y rápidos realizados en la reducción de la pobreza de los niños, gracias a la instauración de créditos de impuestos generosos y dirigidos a ciertos colectivos, la realización del objetivo de erradicación para el horizonte 2020 no avanza. La reducción de la pobreza por el umbral de desarrollo de las rentas no es viable después del incremento considerable de la deuda generada por la crisis económica y financiera. Esta constatación plantea la cuestión de los instrumentos de una política que actúe directamente sobre las causas de la pobreza, tales como el fracaso escolar, el trabajo a jornada parcial o el trabajo discontinuo.

\subsection{El desafío de la crisis}

La crisis económica actual se traduce en un incremento de los beneficiarios de las rentas mínimas. Según un estudio solicitado por el Alto Comisario para las Solidaridades Activas contra la Pobreza al CREDOC ${ }^{21}$, en 2008, a propósito de las consecuencias de la crisis sobre los hogares -especialmente los más modestos-, el presupuesto es cada vez más ajustado. El 56\% de estos hogares declara tener menos de $250 €$ mensuales una vez pagados los gastos fijos y el $15 \%$ se encuentra incluso en una situación de déficit. Además, cerca del $70 \%$ de los hogares pobres consideran que, con la renta total disponible, tienen dificultades para salir adelante, frente al $32 \%$ para el conjunto de la población. Un tercio de las familias pobres considera incluso que tendrá grandes dificultades. El $41 \%$ de estas familias tiene un crédito o una hipoteca en el momento de la encuesta y el $61 \%$ considera que los reembolsos representan una carga importante. El 10\% de los hogares pobres ha solicitado un préstamo durante el último año y el $61 \%$ lo ha hecho para realizar un gasto básico. Por último, el $16 \%$ de las familias pobres se considera en situación de sobreendeudamiento, aunque solamente un tercio haya solicitado una ayuda por sobreendeudamiento a las administraciones públicas.

Asimismo, la mitad de las familias pobres tiene la impresión de encontrarse con más dificultades que hace tres meses para salir adelante y el $70 \%$ tiene más problemas que hace un año. Las razones que explican este endurecimiento varían, puesto que si para el conjunto de la población está vinculado a un aumento del gasto, para los pobres está asociado a la vez a la disminución de los recursos y a un incremento del gasto. En este sentido, el 40\% de los hogares pobres ha utilizado sus ahorros para equilibrar su presupuesto, sabiendo que únicamente el $5 \%$ de estas familias ha podido ahorrar a lo largo de los últimos cinco meses. Además, el $52 \%$ de las familias pobres ha anulado o retrasado un gasto importante por razones financieras y cerca de un tercio de estos hogares ha renunciado a la atención médica.

Conviene subrayar que el $51 \%$ de las familias pobres se ha impuesto más restricciones que de costumbre, especialmente en las vacaciones y actividades de 
ocio, el vestido y el equipamiento doméstico. Entre los más pobres, es preciso añadir a estos tres gastos el teléfono y la alimentación. Los hogares pobres que se han impuesto a sí mismos unas restricciones lo hacen sobre todo porque su situación actual les obliga. Así, el 60\% de los hogares han cambiado sus hábitos alimenticios por razones presupuestarias, y si todo el mundo evita los productos más caros, elige unas tiendas o unas marcas más baratas y sale menos, los más pobres restringen más que los demás su consumo de carne y de pescado, de fruta y de legumbre, se saltan más a menudo las comidas o disminuyen las cantidades. Y, por supuesto, restringen las salidas durante la noche y el fin de semana (53\%), así como la compra de libros, discos, DVD y videojuegos (62\%).

Para terminar, el 55\% de las familias pobres compara más los precios que de costumbre y el $44 \%$ realiza sus compras en las tiendas hard discount. Simultáneamente, el 59\% declara que se gastará menos dinero en las próximas Navidades. En definitiva, el 54\% de estos hogares ha modificado su comportamiento de manera notable desde hace tres meses y manifiesta una mayor preocupación que el conjunto de la población a propósito de su situación personal. La mitad de las personas interrogadas se muestra muy preocupada por el poder adquisitivo de los ciudadanos, la situación de las empresas galas y el futuro del país. Pero, sobre todo, la mitad de las familias pobres se muestra muy preocupada por su poder adquisitivo y el $41 \%$, por su situación profesional ${ }^{22}$.

En este sentido, la crisis actual ha provocado un incremento notable de los hogares que se benefician de las rentas mínimas, lo cual ha creado unos importantes déficits y ha puesto a los departamentos galos en una situación presupuestaria delicada.

\section{Conclusión}

Recordemos que, tras situar el debate sobre las rentas mínimas en el contexto europeo, este artículo ha analizado las rentas mínimas en Francia. La creación de la renta mínima de inserción (RMI) por el gobierno de Michel Rocard constituye la culminación de un proceso histórico que rompe con las lógicas categoriales. Más allá, el balance de las rentas mínimas está afectado por su complejidad y por el fracaso relativo de las políticas de inserción que acompañan la RMI. La renta de solidaridad activa (RSA) responde a la cuestión de las «trampas de inactividad», pero no pone fin a los debates sobre la arquitectura de las prestaciones mínimas y el rol de la redistribución en la lucha contra la pobreza.

Dicho de otra forma, el sistema francés de prestaciones sociales ha entrado en una fase de profunda reestructuración. Veinte años después de la creación de

22. Esta encuesta ha sido realizada por teléfono entre el 26 de noviembre y el 6 de diciembre de 2008. Han sido interrogadas dos muestras sobre la base de un solo cuestionario: una muestra de 1.000 hogares representativos del conjunto de las familias metropolitanas y una muestra de 300 familias representativas de aquellos que viven por debajo del umbral de la pobreza. 
la RMI, la renta de solidaridad activa (RSA) ha sido puesta en marcha con tres objetivos principales: incitación al trabajo, simplificación de los dispositivos y lucha contra la pobreza. El futuro nos dirá si la nueva prestación cumple estos objetivos, pero ya puede observarse que la coordinación coherente de las rentas mínimas está todavía en sus inicios. Por lo tanto, es fundamental proseguir ese movimiento aclarando los objetivos, unificando las reglas y armonizando las cuantías de las diferentes prestaciones. Las dificultades son reales, porque cualquier cambio en una financiación constante corre el riesgo de perjudicar a ciertas personas pertenecientes a colectivos vulnerables. No obstante, estas evoluciones son fundamentales para dar su plena efectividad a una política pública a menudo cuestionada.

Las carencias de este dispositivo ponen de manifiesto la actualidad de la idea de renta básica de ciudadanía (RBC) lanzada en 1986 por los filósofos belgas Philippe Van Parijs (2000) y Robert der Veen, y que se beneficia de la adhesión de varios intelectuales de reconocido prestigio tales como los premios Nobel de Economía James Meade, Herbert Simon y James Tobin (1967). Como lo subraya Daniel Raventós, en su libro titulado El derecho a la existencia (1999), con el pago de la renta básica de ciudadanía se solucionarían los siguientes problemas: evitaría que las personas tuvieran que elegir entre la RBC y un empleo; al convertirse en una renta garantizada, permitiría que todo el mundo pudiera contar con una cantidad de dinero constante, aunque fuera modesta, y así hacer proyectos y tener una mayor movilidad; y supondría también una simplificación administrativa, tanto por la ampliación de derechos como por el control.

En el caso francés, supondría un avance, sobre todo para tres sectores de la población: 1) los jóvenes menores de veinticinco años que no se benefician de las prestaciones mínimas, a pesar de vivir a menudo en unas condiciones precarias, especialmente cuando los vínculos familiares son inexistentes; 2) los inmigrantes, sobre todo los denominados «sin papeles», que carecen del permiso de residencia y de trabajo y que necesitan una ayuda de emergencia para satisfacer sus necesidades básicas, como pueden ser la alimentación, el alojamiento, el trabajo o el cuidado de los niños, y 3) los jubilados, que disponen de pequeñas pensiones, insuficientes para poder vivir en condiciones dignas.

Francia se encuentra en condiciones favorables para instaurar la renta básica de ciudadanía por varias razones, siempre y cuando exista una voluntad política y en la medida en que se resuelvan los problemas técnicos que condicionan su aplicación. Estas razones se pueden condensar en cinco puntos. En primer lugar, la cultura republicana, profundamente enraizada tanto en las instituciones y en la cultura política como en la mentalidad de la población, insiste sobre el principio de igualdad, ya que Libertad, Igualdad y Fraternidad constituyen los pilares fundamentales del modelo francés. En segundo lugar, la elaboración y la posterior implementación tanto de la RMI como de la RSA abren el camino a la instauración de la RBC. En este sentido, la renta básica de ciudadanía supondría un paso más en la lucha contra la pobreza y la exclusión social. En tercer lugar, existe un precedente con la cobertura médica universal (CMU), 
aprobada bajo el gobierno de Lionel Jospin, que extiende el derecho de recibir una atención médica a todos los ciudadanos, independientemente de su condición socioeconómica y de su situación legal. En cuarto lugar, ante la crisis financiera y económica, que se ha convertido en crisis social con el incremento del paro y de la precariedad laboral, el modelo social francés ha demostrado una fortaleza relativa, por lo cual, la aprobación de la RBC permitiría atenuar los efectos de la crisis y mantener así la cohesión social. Y, en quinto lugar, la aprobación de la RBC supondría la reafirmación y la relegitimación del pacto social en torno a unos principios básicos y evitaría un divorcio, que acabaría siendo insalvable, entre las élites políticas y la ciudadanía.

\section{Referencias bibliográficas}

Actualités Sociales Hebdomadaires (2005). «Enquête sur la décentralisation du RMI, deux ans après». Cahier spécial 50 ans ASH, 12, noviembre-diciembre.

Agence Nouvelle des Solidarités Actives (2008). Étude sur l'accés au RSA des bénéficiaires de l'ASS et de l'ARE.

Aust, A. y Arriba, A. (2004). "Policy Reforms and discourses in social assistance in the 1990s: Towards Activation». Estudio presentado en ESPAs Annual Conference. Oxford.

Avenel, M. (2005). «Les modes d'organisation adoptés par les conseils généraux pour la gestion du RMI suite à la décentralisation». DREES, Études et Résultats, 432, octubre.

Ayala, L. (2000a). Las rentas minimas en la reestructuración de los estados de bienestar. Madrid: Consejo Económico y Social.

- (2000b). «Las rentas mínimas en el Estado de bienestar español». En: MuÑoz DE Bustillo, E. (eds.). El Estado de bienestar en el cambio de siglo. Madrid: Alianza.

Ayala, L. y Rodríguez Coma, M. (2003). La duración en los programas de lucha contra la pobreza. Madrid: Instituto de Estudios Fiscales.

Behrendt, C. (2003). "¿Programas de rentas mínimas y la reducción de la pobreza: una red de seguridad defectuosa?». En: Guillén, A.M. y Álvarez García, S. (coord.). Viejas y nuevas desigualdades: retos para la protección social. Madrid: Thomas-Civitas.

Belorgey, J.-M. (2000). Minima sociaux, revenus d'activité, précarité. París: La Documentation Française.

Cahuc, P. (2009). Les réformes ratées du président Sarkozy. París: Flammarion.

Capucha, L. (1998). Rendimento minimo garantido: avaliaçao da fase experimental. Lisboa: CIES/MTS.

Castel, R. (1995). La métamorphose de la question sociale, une chronique du salariat. París: Fayard.

CNAF (2007). "La Décentralisation du RMI trois ans après: Enquête auprès des CAF». Dossier d'Étude, 97, octobre.

Comisión Europea (1993). Libro blanco sobre crecimiento, competitividad y empleo. Bruselas.

- (2006). Concerning a consultation on action at EU level to promote the active inclusion of the people furthest from the labour market. [www.europa.eu]

Commissariat Général au Plan (2000). Minimas sociaux, revenu d'activité et précarité. Rapport du Commissariat général au plan coordonné par Jean-Michel Belorgey. 
Commission Familles, Vulnérabilité, Pauvreté (2005). Au possible, nous sommes tenus. La nouvelle équation sociale. París: Rapport du CNLE.

CREDOC (2006). «Les actifs en situation de pauvreté: quelles expériences de la pauvreté». Cahier de Recherche, 227, noviembre.

Damon, J. (2002). La question SDF. París: PUF.

- (2008). L'exclusion. París: PUF.

De Giorgi, G. y Pellizzari, M. (2006). «Welfare migration in Europe and the cost of a harmonized social assistance». IZA Discussion Paper, 2094.

DRESS (2007). "Les politiques d'insertion des conseils généraux en direction des bénéficiaires du RMI». Etudes et Résultats, 582.

DREES (2007). «Les allocations de minima sociaux en 2006». Études et Résultats, 617, diciembre.

DREES (2007). «Le nombre d'allocataires du RMI au 30 septembre 2007». Études et Résultats, 613, diciembre.

EAPN (European Anti-Poverty Network) (2005). ¿Puede contribuir la activación a la inclusión social?: Criterios para una buena activación según EAPN. [www. eapn.horus.be]

- (2006). Ensuring a Decent Income and a Better Life for All. [www.eapn.horus.be]

EuzéBy, CH. (2004). "La activación francesa de las personas en situación de desempleo y de los beneficiarios de la asistencia pública: entre el workfare anglosajón y la inserción escandinava». Encuentro Renta Básica y Procesos de Inserción. Vitoria.

FNARS (2006). Les exclus de l'emploi et les travailleurs pauvres. Libro blanco, junio.

Gomel, B. y Steverin, E. (2009). Expérimenter pour décider?: Le RSA en débat. Noisyle-Grand: Centre d'Études de l'Emploi.

Hanesch, W. y Balzter, N. (2001). Activation Policies in the Context of Social Assistance. [www.stakes.fi]

Hirsch, M. et al. (2005). Au possible nous sommes tenus: Rapport de la commission Familles, vulnérabilité, pauvreté. París: Ministère des Solidarités, de la Santé et de la Famille.

Hirsch, M. y Villeneuve, S. (2006). La pauvreté en héritage, 2 millions d'enfants pauvres en France. París: Robert Laffont.

IGAS (2006). Evaluation de la loi du 18 décembre 2003 décentralisant le RMI et créant le $R M A$.

- (2009). Mission de contrôle des politiques d'insertion menées en faveur des allocataires de RMI.

Inspection Générale des Affaires Sociales (2006). Evaluation de la loi $n^{\circ} 2003-$ 1-200 du 18 décembre 2003 décentralisant le RMI et créant le RMA, noviembre.

Kazepov, Y. y Sabatinelli, S. (2005). "The Belgium Droits à l'intégration sociale (DIS) in a European Perspective». Peer Review Meeting. Bruselas.

Laparra, M. (2004a). "Las rentas mínimas en España». Encuentros Renta Básica y Procesos de Inserción. Vitoria.

- (2004b). «La travesía del desierto de las rentas mínimas en España». Documentación social, 135, 57-76.

Laparra, M.; Corera, C.; García, C.; Macías, A.; Orte, P. y García Serrano, C. (2003). La garantía de ingresos en Navarra. Estudio evaluativo de la renta básica 1990-2001. [www.cfnavarra.es/DGBS/planificacion/renta_basica/RentaBasica.pdf]

Lenoir, R. (1974). Les exclus. Un français sur dix. París: Seuil.

Moreno, G. (2008). Crisis y reconstrucción del Estado de bienestar. Vitoria: Gobierno Vasco. 
Nicaise, I.; Groenez, S.; Adelman, L.; Roberts, S. y Middleton, S. (2004). Gaps, traps and springboards in the floor of social protection systems. A comparative study of 13 EU countries. [www.sidos.ch]

Observatoire National de la Pauvreté et de l'Exclusion Sociale (2008). Rapport 2007-2008. París: La Documentation Française.

ODAS (2004). La décentralisation du dispositif RMI et la mise en қeuvre du RMA dans les départements, mayo.

Paugam, G. (1996). L'exclusion: l'état des savoirs. París: La Découverte.

Peña-Casas, R. (2005). «Once millones de trabajadores pobres en Europa». Hilero Eguneratuz, 54, 6-7.

Pérez Eransus, B. (2004). «La activación como estrategia de lucha contra la exclusión social». Documentación Social, 134, 125-141.

Raventós, D. (1999). El derecho a la existencia. Barcelona: Ariel.

- (2000). «El salario de toda la ciudadanía». Claves de Razón Práctica, 106.

Rigaudiat, J. (2009). «Le RSA, en avant vers le passé». Droit Social, 3, 315-319.

Rosanvalon, P. (1995). La nouvelle question sociale. París: Seuil.

Social Plateform (2006). Achieving Effective Minimum Income and Active inclusion policies in the EU: What the European Union can Contribute. [www.socialplateform.org]

Thevenet, A. (1994). RMI, théorie et pratique. París: Bayard.

Tobin, J.; Pechman, J.A. y Mieszkowski, P.M. (1967). «Is a Negative Income Tax Practical». The Yale Law Journal, 77 (1), p. 1-27.

Unión Europea (1992). Recomendación 92/441/CEE del Consejo de 24 de junio de 1992, sobre los criterios comunes relativos a los recursos y prestaciones suficientes en los sistemas de protección social. [www.europa.es]

UrTEAGA. E. (2009a). «Las políticas de lucha contra la pobreza y la exclusión social en Francia». Zerbitzuan, 45, 7-21.

- (2009b). «Fundamentos y organización de las políticas sociales en Francia». Portularia, 9 (2), 75-95.

Van Parijs, P. (2000). «A Basic Income for All». Boston Review, octubre-noviembre 2000. [www.bostonreview.net] 